\title{
Variation in number and position of nutrient foramen of clavicle - A morphological study in western Rajasthan
}

\author{
Dinesh Kumar ${ }^{1}$, Leena Raichandani ${ }^{2}$, Sushma K Kataria $^{3}$, Jaskaran Singh $^{4}$ \\ ${ }^{1}$ Postgraduate, ${ }^{2}$ Senior Professor, ${ }^{3}$ Senior Professor and HOD, ${ }^{4}$ Asssitant Professor, Dept. of Anatomy, Dr. S.N. Medical \\ College, Jodhpur, Rajasthan, India
}

*Corresponding Author: Dinesh Kumar

Email: choudharyyydinesh@gmail.com

\begin{abstract}
Introduction: The clavicle is a modified long bone. It is the most important bone for transmission of weight from upper limb to the axial skeleton. It supports the shoulder so that the arm can swing clearly away from the trunk.

Materials and Methods: The study included 102 adult clavicles 52 right sides and 52 left side which were obtained from the department of the Anatomy Dr. S.N. Medical College Jodhpur. The age and sex of the clavicles were not determined. All the bones were grossly observed for the number, location and direction of the nutrient foramina. The data were collected and morphologically analysed.

Results: In our Present study Nutrient foramina were present in 50 clavicles (Right) and 44 clavicles (left). Out of which single foramina in 41 clavicles (Right) and 36 clavicles (Left), double foramina in 9 clavicles (Right) and 6 clavicles (left) and three foramina in 2 clavicles (Left). Absence of nutrient foramina were found in 2 clavicles (Right) and 8 clavicles (Left). Maximum number was present in the medial 2/3 and on the posterior surface of 46 bones (Right) and 34 Bones (Left). All foramina were directed towards the acromial end.

Conclusion: The knowledge of nutrient foramina in clavicles is important for surgical procedures such as bone grafting and in microsurgical vascularized bone transplantation.
\end{abstract}

Keywords: Nutrient foramina, Clavicle, Bone graft.

\section{Introduction}

Human beings are bestowed with the power of bipedal locomotion and the clavicle acts as a strut to allow the free movement of the upper limb away from the chest wall. Bones are structures that adapt to their mechanical Environment, and from a foetal age adapt to the presence of naturally occurring holes. These holes or nutrient foramina, allow blood vessels to pass through the bone cortex. ${ }^{1}$

The nutrient artery is the principal source of blood supply to a long bone, particularly important during its active growth period in the embryo and foetus, as well as during the early phase of ossification. ${ }^{2}$

Nutrient foramen is the largest foramen on the long bones through which nutrient artery for that bones passes. ${ }^{3}$ The Clavicle is a modified long bone placed horizontally and subcutaneously at the root of neck. It also transmits the weight from upper limb to the axial skeleton.
The inferior surface of shaft of clavicle presents a subclavian groove. A Nutrient foramen lies at the lateral end of the groove running in a lateral direction. It was described that a small foramen may be present in the middle one third of the clavicle, along its superior border. This foramen transmits the nutrient artery and at times, the supraclavicular nerve. ${ }^{4}$

In the radiological literature it was described that this foramen transmits medial fascicle of the supraclavicular nerve. Anatomically it was described that this foramen was present in 2- $6 \%$ of the population. ${ }^{5}$

The knowledge of nutrient foramen is important in surgical procedures like bone grafting and more recently in microsurgical vascularized bone transplantation. As these techniques are becoming popular, information relating to the anatomical description of these foramina is of vital importance to preserve the circulation of affected bony structure. ${ }^{6}$ 


\section{Materials and Methods}

This study was conducted on 102 (51right \& 51left) adult human cleaned and dried Clavicles in Department of Anatomy, Dr. S. N. Medical College, Jodhpur. The specific age \& sex characteristics of the bones studied were unknown. Bones which have gross pathological deformities were excluded from the study.

Following Observation were recorded with the help of (a). Magnifying lens (b).

All the bones were macroscopically observed for the number, location and direction of the nutrient foramina. A magnifying lens was used to observe the foramina. The data were collected and morphologically analysed. The distance of foramina from sternal end was also determined. The mean length of the clavicle also was determined.

\section{Observations and Results}

In our Present study Nutrient foramina was present in 94 clavicles, 50 clavicles (Right) and 44 clavicles (left). Out of which single foramina in 77 clavicles, 39 clavicles (Right) and 36 clavicles (Left), double foramina in 15 clavicles, 9 clavicles (Right) and 6 clavicles (left) and three foramina in 2 clavicles (Left). Absence of nutrient foramina were found in 10 clavicle, 2 clavicles (Right) and 8 clavicles (Left).

Maximum number was present in the medial 2/3 and on the posterior surface of 66 clavicle, 32 bones (Right) and 34 Bones (Left). All foramina were directed towards the acromial end.

Table 1: Numbers of N.F. in studied Clavicles

\begin{tabular}{|l|c|c|c|}
\hline No. of foramina & Right & Left & Total \\
\hline Absent & 2 & 8 & 10 \\
\hline One & 39 & 36 & 75 \\
\hline Two & 9 & 6 & 15 \\
\hline Three & 0 & 2 & 2 \\
\hline More than Three & 0 & 0 & 0 \\
\hline
\end{tabular}

Table 2: Morphological \& distribution of nutrient foramina in clavicles

\begin{tabular}{|c|c|c|c|c|c|c|c|}
\hline \multirow{2}{*}{$\begin{array}{l}\text { Side of } \\
\text { clavicle }\end{array}$} & \multicolumn{4}{|c|}{ Medial 2/3 } & \multicolumn{2}{|c|}{ Lateral 1/3 } & \multirow[t]{2}{*}{ Total } \\
\hline & Superior & Inferior & Posterior & Anterior & Superior & Inferior & \\
\hline Right & 0 & 3 & 45 & 0 & 0 & 0 & 48 \\
\hline Left & 0 & 10 & 34 & 0 & 0 & 0 & 44 \\
\hline Total & 0 & 13 & 79 & 0 & 0 & 0 & 92 \\
\hline
\end{tabular}

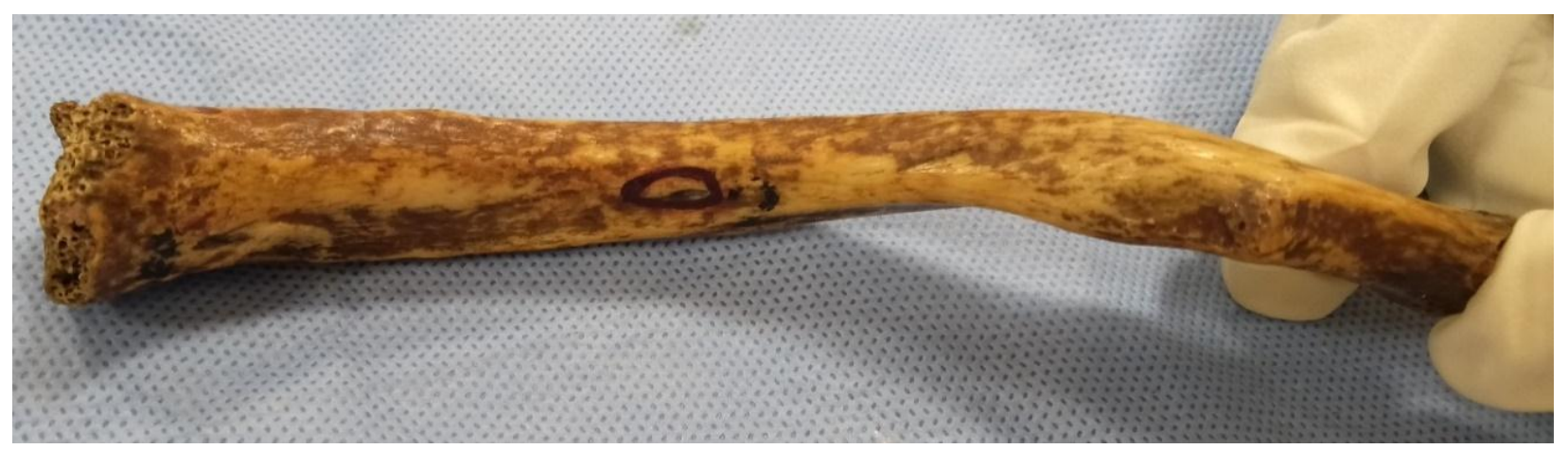

Fig. 1: Right side showing one foramina 


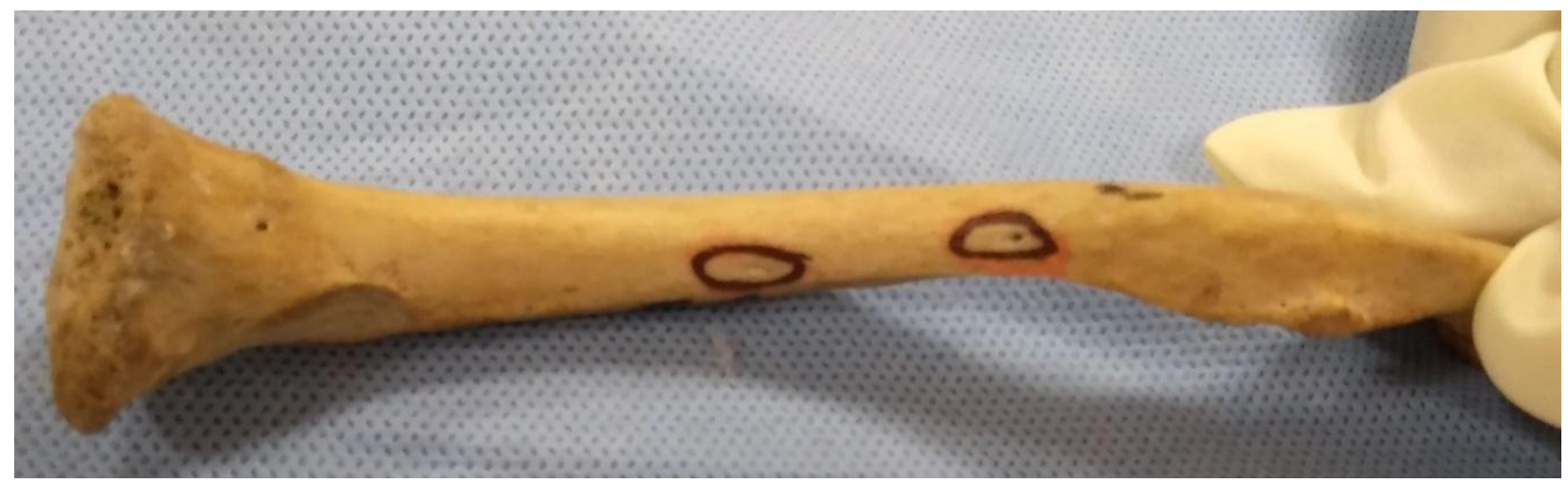

Fig. 2: Right side clavicle showing two foramina

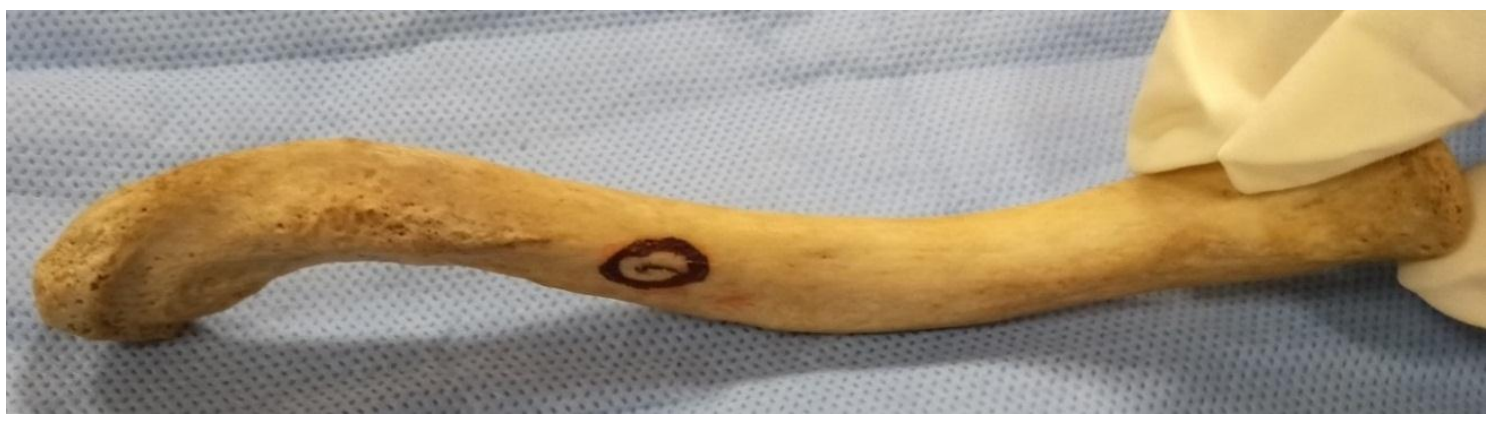

Fig. 3: Left side showing one foramina

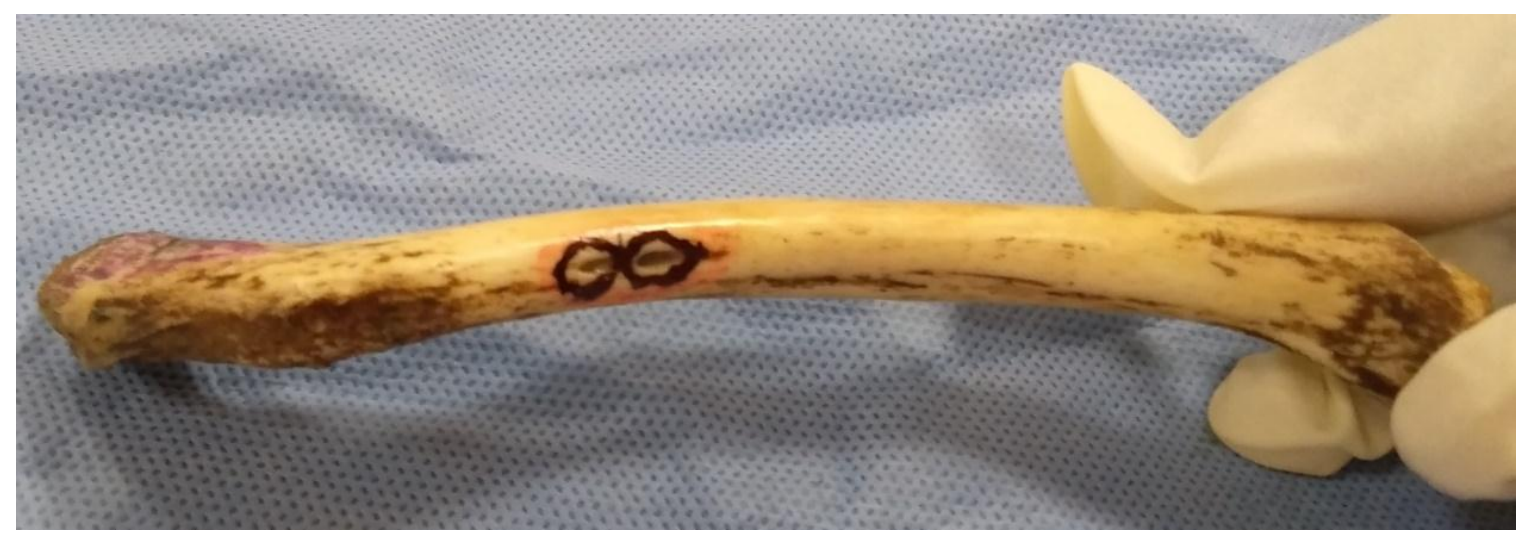

Fig. 4: Left side showing two foramina

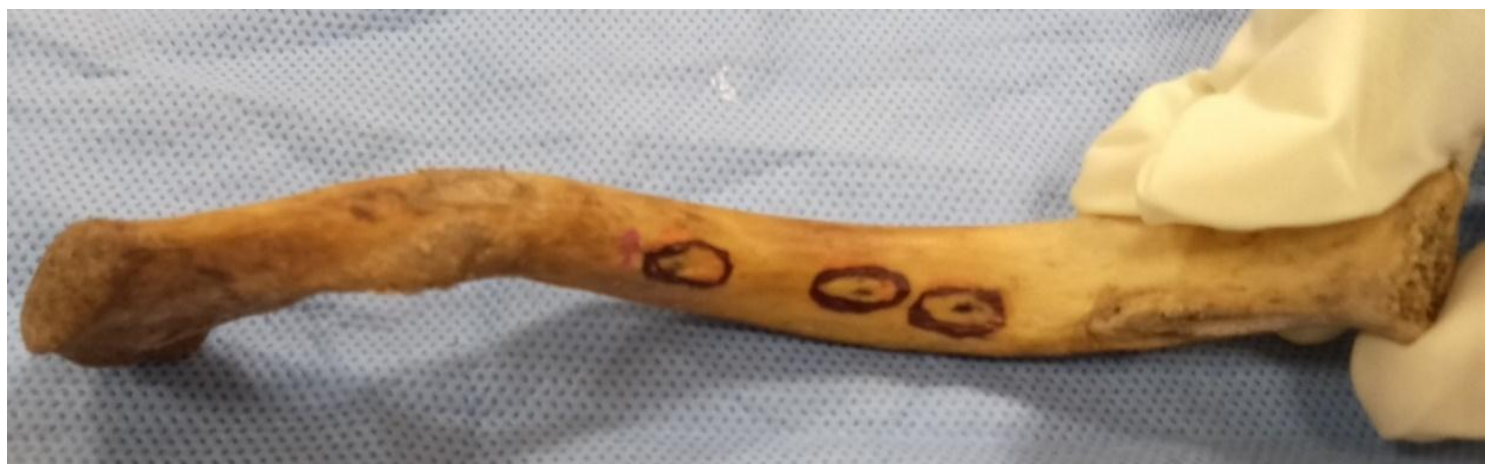

Fig. 5: Left side showing tree foramina 
Table 3

\begin{tabular}{|c|c|c|c|c|}
\hline Number of foramina & $\begin{array}{c}\text { Mulukar et al, } \\
\mathbf{2 0 1 1}\end{array}$ & $\begin{array}{c}\text { Murlimanju et al } \\
\mathbf{2 0 1 4}\end{array}$ & Rahulral et al,2014 & Present study \\
\hline 0 & - & - & - & $9.80 \%$ \\
\hline 1 & $68 \%$ & $38.5 \%$ & $42 \%$ & $73.52 \%$ \\
\hline 2 & $20 \%$ & $44.2 \%$ & $52.5 \%$ & $14.70 \%$ \\
\hline$>2$ & $11 \%$ & $13.4 \%$ & $6 \%$ & $1.96 \%$ \\
\hline Position & $1.4 \%$ & $1.9 \%$ & - & - \\
\hline Superior surface & $41.5 \%$ & $55.8 \%$ & $35.4 \%$ & $14.13 \%$ \\
\hline Inferior surface & $56.3 \%$ & $69.2 \%$ & $64.6 \%$ & $85.86 \%$ \\
\hline Posterior surface & Towards acromial & $\begin{array}{c}\text { Toward acromial } \\
\text { end }\end{array}$ & Toward acromial end & $\begin{array}{c}\text { Toward } \\
\text { acromial end }\end{array}$ \\
\hline $\begin{array}{c}\text { Direction of nutrient } \\
\text { canal }\end{array}$ & \begin{tabular}{c} 
end \\
\hline
\end{tabular} & & &
\end{tabular}

\section{Discussion}

The nutrient foramen is defined as the largest foramen present on the shaft of long bone allowing nutrient artery to enter the bone, the role of which is important in providing nutrition and growth of long bones. Healing of fractures, as of all wounds, is dependent upon blood supply. ${ }^{7}$ According to Watson-Jones Injuries to the nutrient arteries during fracture predisposing to faulty union. ${ }^{8}$

Recent studies confirmed that vascularizes bone and joint allograft survival depends strongly on blood supply of bone. So the knowledge of nutrient foramen is important for orthopaedic surgeons during open reduction of fracture, in order to avoid injury of nutrient artery. ${ }^{9}$

The major blood supply to long bones usually enters at particular points on shaft that determines the number of nutrient foramen.

In the present study single nutrient foramen present in $75(73.52 \%$ ) clavicles, two foramen present in $15(14.70 \%)$ clavicles, three foramen present in $2(1.96 \%)$ clavicles, foramen absent in $10(9.80 \%)$ clavicles and more than three foramen was not found.

According to Malukar O, Joshi $\mathrm{H}$ studies 68\% clavicle has single foramen, $20 \%$ clavicle has two foramen, $11 \%$ clavicle has more than two foramen and absence of nutrient foramen not found ${ }^{10}$ but in studies of Rahul Rai et al only $42 \%$ of bone had single foramen and $52.5 \%$ of bone were with double foramen. ${ }^{11}$ Murlimaju BV et al Studies that nutrient foramen in clavicle was directed towards the acromial end. $^{12}$

So according to previous studies and present study clavicle usually has single nutrient foramen but some clavicle has two, three and absence of nutrient foramen.

\section{Conclusion}

Knowledge nutrient foramen of clavicle is helpful to preserve the arterial supply during radiation therapy, internal of fixation devices and in free vascularised bone graft, so knowledge about nutrient foramen is clinically important.

\section{Source of funding}

None.

\section{Conflict of interest}

None.

\section{References}

1. Gotzen N., Cross A., IFJU P., Rapoff A. Understanding stress concentration about a nutrient foramen. $J$ Biomech 2003;36:1511-21.

2. Lewis, O.J. (1956). The blood supply of developing long bones with special reference to the metaphysic. $J$ Bones $J t$ Surg 1956;38:928-33.

3. Chatrapathi DN. Mishra BD. Position of nutrient foramen on the shaft of the human long bones. $J$ Anatomical Soc India 1965;14:54-63.

4. Kumar R, Lindell MM, Madewell JE, David R, Swischuk LE. The clavicle: Normal and abnormal. Radiographics 1989;9:677-706. 
5. Freyschmidt J, Sternberg A, Brossmann J, Wiens J (2003) Borderlands of normal and early pathological findings in skeletal radiography, 5th edn. Thieme, New York, p 305318.

6. Lewis O.J. The blood supply of developing long bones with special reference to the metaphysic. J Bones Jt Surg 1956;38:928-33.

7. Johnson R. W. A Physiological study of the Blood Supply of the Diaphysis. J Bone Jt Surg 1927;9:15.

8. Watson-Jones, Sir R. Fractures and Joint Injuries, 4th Edition. Edinburgh and London: E. \& S. Livingstone Ltd., 1955.

9. Joshi H, Doshi B, Malukar O. A study of the nutrient foramina of the humeral diaphysis. NJIRM 2011;2:14-17.

10. Ojaswini Malukar, Hemang Joshi, Diaphysial Nutrient Foramina in long Bones sand Miniature Long Bones. NJIRM 2011;2(2):23-6.
11. Rahul Rai, Shailaza Shrestha, B Kavitha (2014) Morphological and topographical anatomy of nutrient foramen in clavicles and their clinical importance. IOSR J Dent Med Sci 2014;13(1):37-40.

12. Murlimanju BV, Prabhu LV, Pai MM, Yadav A, Dhananjaya KV, Prashanth KU. Neurovascular foramina of the human clavicle and their clinical significance. Surg Radiol Anat 2011;33(8):679.

How to cite this article: Kumar D, Raichandani L, Kataria SK, Singh J. Variation in number and position of nutrient foramen of clavicle - A morphological study in western Rajasthan. Indian $J$ Anat Surg Head Neck Brain 2019;5(3):67-71. 